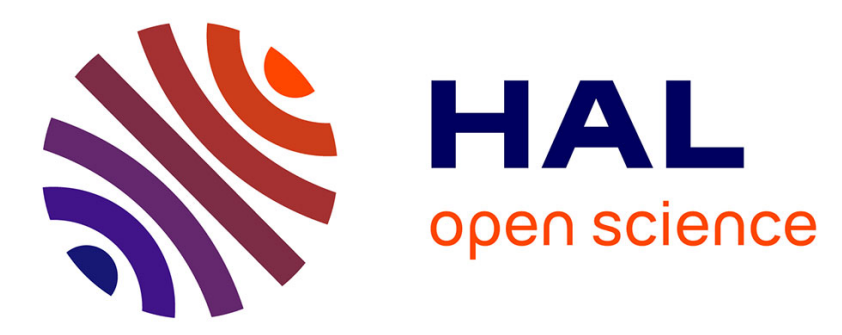

\title{
Tubular gas preconcentrators based on inkjet printed micro-hotplates on foil
}

\author{
El Hadji Malik Camara, Philippe Breuil, Christophe Pijolat, Jean-Paul \\ Viricelle, Nicolaas F de Rooij, Danick Briand
}

\section{- To cite this version:}

El Hadji Malik Camara, Philippe Breuil, Christophe Pijolat, Jean-Paul Viricelle, Nicolaas F de Rooij, et al.. Tubular gas preconcentrators based on inkjet printed micro-hotplates on foil. Sensors and Actuators B: Chemical, 2016, 236, pp.1111-1117. 10.1016/j.snb.2016.06.121 . hal-01337348

\section{HAL Id: hal-01337348 https://hal.science/hal-01337348}

Submitted on 26 Aug 2016

HAL is a multi-disciplinary open access archive for the deposit and dissemination of scientific research documents, whether they are published or not. The documents may come from teaching and research institutions in France or abroad, or from public or private research centers.
L'archive ouverte pluridisciplinaire $\mathbf{H A L}$, est destinée au dépôt et à la diffusion de documents scientifiques de niveau recherche, publiés ou non, émanant des établissements d'enseignement et de recherche français ou étrangers, des laboratoires publics ou privés. 


\title{
Tubular gas preconcentrators based on inkjet printed micro- hotplates on foil
}

\author{
M. Camara ${ }^{\mathrm{a}}$, P. Breuil ${ }^{\mathrm{b}}$, C. Pijolat ${ }^{\mathrm{b}}$, J. P. Viricelle ${ }^{\mathrm{b}}$, N.F. de Rooija ${ }^{\mathrm{a}}$, D. Briand ${ }^{\mathrm{a}}$ \\ ${ }^{a}$ Ecole Polytechnique Fédérale de Lausanne (EPFL), Institute of Microengineering (IMT), Sensors, Actuators and Microsystems Laboratory \\ (SAMLAB), Rue de la Maladière 71b, 2000 Neuchâtel, Switzerland \\ ${ }^{b}$ Ecole Nationale Supérieure des Mines de Saint-Etienne, SPIN-EMSE, CNRS: UMR5307, LGF, 42023 Saint-Etienne, France
}

\begin{abstract}
This paper presents the design and implementation of a foil gas preconcentrator (FGP) based on a gold microhotplate inkjet printed on a polyimide (PI) substrate. The device is made on flexible foil using printing whereas all preconcentrators seen in literature are mainly based on rigid substrates and are micro-machined using cleanroom processes. Printing allows the additive and localized deposition of materials at low temperature on large area and can be applied to both the patterning of the heating element and the integration of the gas absorbent material. The benefits are the easy and flexible processing of cost-effective and lightweight preconcentrators for a variety of target gases. The tubular shape of the FGP is obtained by rolling up and sealing the inkjet printed gold hotplate on foil, which is then filled with the gas absorbent material (Carbopack B and Tenax). The diameter of the inlet/outlet of FGP is adjustable leading to high flow rates, up to $1.5 \mathrm{~L} / \mathrm{min}$, much larger than their silicon counterpart. The concept was validated using four target gases (benzene, toluene, nitrobenzene and acetophenone) at concentrations down to $250 \mathrm{ppb}$. For example, the duty cycle of the FGP was reduced down 1 min and a preconcentration factor of 200 was obtained after an adsorption on Carbopack B of 250ppb of toluene during $2 \mathrm{~min}$ at $1 \mathrm{~L} / \mathrm{min}$.
\end{abstract}

Keywords: Gas preconcentration, Inkjet printing, Polymeric foil, Micro-hotplates, Printed preconcentrator, Pollution monitoring

\section{Introduction}

The use of pre-concentration devices has become common-place in development of handheld detectors for enhancing both their sensitivity and selectivity $[1,2,3]$. Indeed, the preconcentration presents two major advantages. On one hand, it allows enriching the concentration of the target compound by an accumulation effect and on another hand, it acts as a filter from its discrimination capacity. It is schematically characterized by two different phases. The first step corresponds to the adsorption phase during which the target compound is injected through a bed of adsorbent materials for an adsorption reaction. The second step is the desorption phase during which the adsorbent material is heated up for releasing adsorbed compounds. The desorbed gas is then driven into the detector by a low flow rate or just by difference of pressure between the sensor and the preconcentration cells.

As basic principle of operation for gas preconcentrators, a high adsorption flow rate $\left(\mathrm{A}_{\mathrm{f}}\right)$, a low desorption flow rate $\left(\mathrm{D}_{\mathrm{f}}\right)$, a relatively long adsorption time, and a very short desorption time meaning a high heating rate are desired for good preconcentration performance $[4,5]$. The performance of a preconcentrator is characterized by the ratio between concentration after and before preconcentration, namely the preconcentration factor (PF). Beside experimental parameters, the choice of the adsorbent material is also a key factor for enhancing the preconcentrator performance. This selection depends on the type of application, i.e. on the nature of the gases to be detected.

Different designs of preconcentrators have been reported in literature with two major concepts: a close (microchannel device sealed with cover) versus an open (hotplate based device) configuration. Hotplate-based preconcentrators are made with the sensor placed above it enabling the direct desorption of the target compound on the sensor without carrier gas $[6,7,8]$; whereas micro-channel-based preconcentrators are closed with a cover (mainly glass) for confining in a small volume the desorbed gas and thus avoiding any drawbacks related to dilution[3, 5, 6, 9]. However all these devices are silicon-based and processed in a cleanroom environment involving a succession of photolithography, dry etching and bonding steps which are restricted to wafer level and resulted in a high component cost. Meanwhile, our group also reported on cleanroom processed low power micro-hotplates on flexible polyimide foil applied to sensors operating up to $300^{\circ} \mathrm{C}$ [10]. Moreover, we have recently published our work on low cost inkjet printed silver nanoparticles-based micro-hotplates on PEN (Polyethylene naphthalate) foil 
for gas sensors operating at low temperature $\left(<100{ }^{\circ} \mathrm{C}\right)$ [11]. Here we report on high operating temperature printed micro-hotplates for gas preconcentration based on the patterning of gold nanoparticles-based heater on PI foil. We propose a cost-effective process to develop a tubular gas preconcentrator by rolling up a printed micro-hotplate on foil before filling it with an adsorbent. With its adjustable inlet/outlet, our foil gas preconcentrator allows operating at higher flow rates (up to $1 \mathrm{~L} / \mathrm{min}$ ) than silicon devices previously reported. Since this study has been done in the frame work of the EU project SNIFFER which aimed at detecting explosives, illicit drugs, and VOCs for a variety of border security scenarios like smuggling prohibited goods (cigarettes, pills, foods...), the proposed concept was validated by applying it to the preconcentration of benzene, toluene, nitrobenzene and acetophenone (cigarettes additive)..

\title{
2. Design and fabrication
}

\subsection{Design}

The micro-hotplate is made of metallic meander which was $140 \mathrm{~mm}$ long and $600 \mu \mathrm{m}$-wide with a gap of $400 \mu \mathrm{m}$ between its arms. The size of the hotplate i.e. the active area of the FGP was fixed to $15 \times 8 \mathrm{~mm}^{2}$. The foil microhotplate is rolled up and sealed for obtaining the tubular shape of the preconcentrator. The latter is then filled with the desired adsorbent and closed with the fluidic capillaries (Figure 1).

Our device is designed with a large heater area for two reasons:

- On one hand, to obtain a long enough tubular preconcentrator to maximize the adsorption time by increasing the residence time of the target gas when going across the absorbent material;

- On another hand, to be sure that the heater meander covers all the diameter of the FGP in order to avoid any cold area during the heating up of the device for gas desorption. The latter could reduce considerably the preconcentration factor by acting as a second "cold" adsorption site, which would trap again the gas during the desorption phase.

a)

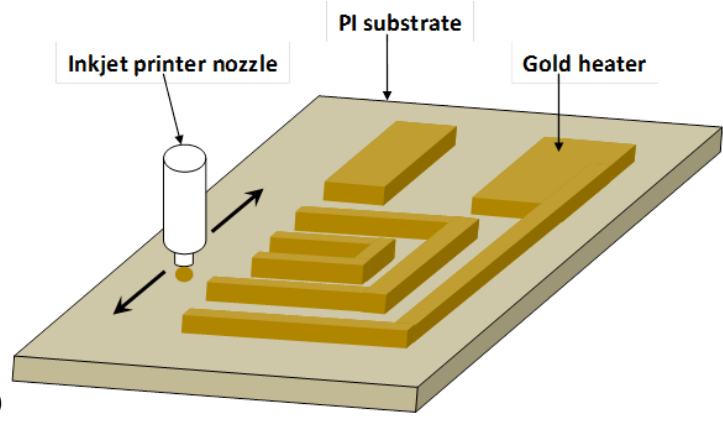

b)

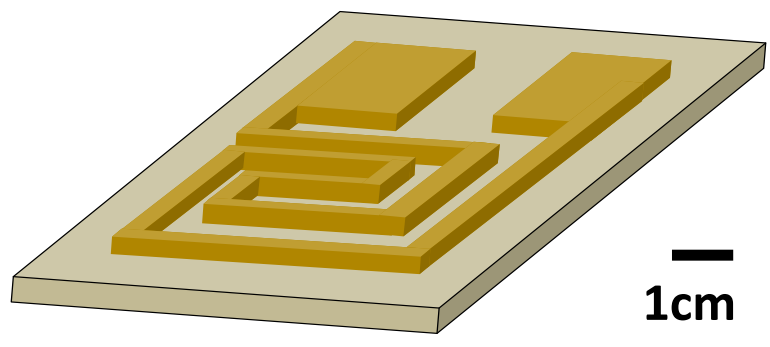

d)

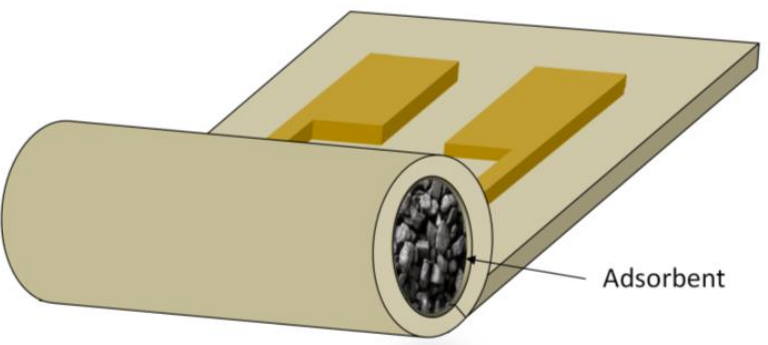

c)

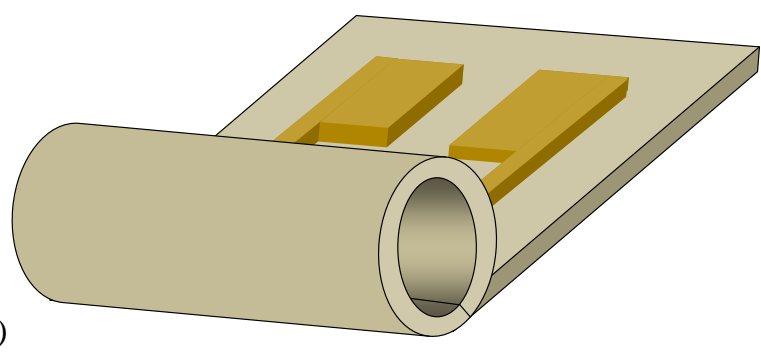

(n)
(n) 


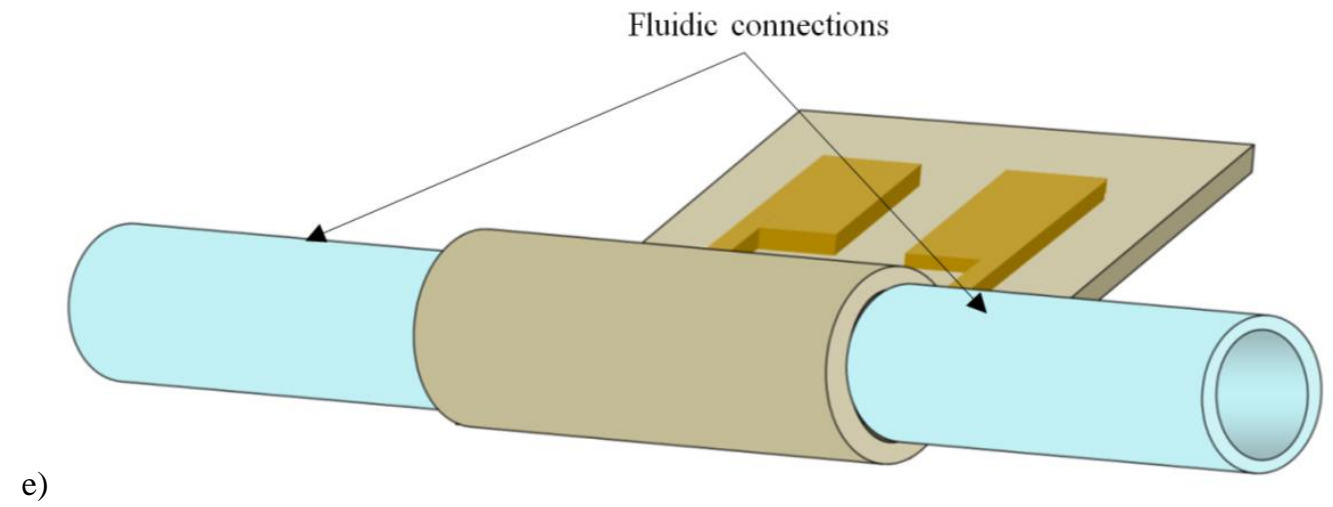

Figure 1: Schematic diagram of the implementation process of our tubular FGP: a) the printing of micro-hotplate b) the printed hotplate c) the rolled up micro-hotplate, d) the insertion of the adsorbent and e) the final FGP with fluidic interconnects.

\subsection{Fabrication}

The micro-hotplate is made by inkjet printing (Dimatix DMP 2800 printer) a gold nanoparticles-based ink (from Harima) on $50 \mu \mathrm{m}$-thick PI foil (Kapton ${ }^{\circledR}$ EN from Dupont). Three layers were consecutively deposited with a drying step at $60^{\circ} \mathrm{C}$ in between for thickening the heater and thus lowering its resistance value for high heating rate. The microhotplate is then sintered at $250^{\circ} \mathrm{C}$ during three hours. The thickness of the gold layer varies between $50 \mathrm{~nm}$ to $1 \mu \mathrm{m}$ from the center to the edges because of the "coffee-ring" effect observed during the drying of the ink. The resistance of the heater is about $50 \Omega$. As mentioned previously, this technique allows inkjet printing multiple hotplates in a row with the possibility of changing designs if needed (Figure 2a).

After the printing step, the micro-hotplate is rolled up and sealed with a high temperature ceramic glue for obtaining a tubular shape (Figure 2b). The gold heater is located on the internal diameter of the tube in direct contact with the adsorbent which is inserted within the tube in granular form. This configuration permits minimizing the heat dissipation while maximizing the desorption rate thanks to the low thermal conductivity of PI substrate $(0.12$ $\left.\mathrm{W} \cdot \mathrm{m}^{-1} \cdot \mathrm{K}^{-1}\right)$ in regards to silicon $\left(149 \mathrm{~W} \cdot \mathrm{m}^{-1} \cdot \mathrm{K}^{-1}\right)$. The resistance of the heater meander is used to deduct and control the temperature of the FGP

Long used in gas chromatography, carbon materials and polymer-based adsorbents are best candidates for the detection of volatile organic compounds (VOCs) $[3,5,12,9,13]$. Therefore, Carbopack B (carbon-based adsorbent) and Tenax TA (polymeric adsorbent) were chosen for their high affinity towards the targeted compounds. The chosen adsorbent material is inserted in the tube in granular form. It is maintained within the tube by plugging the inlet and outlet of the device with fiberglass which is permeable to gases. The implementation of the FGP is completed by the fixation of electric connection wires and the sealing of fluidic capillaries of $1 \mathrm{~mm}$ of internal diameter using electrically conductive adhesive and ceramic glue, respectively (Figure 2c). 

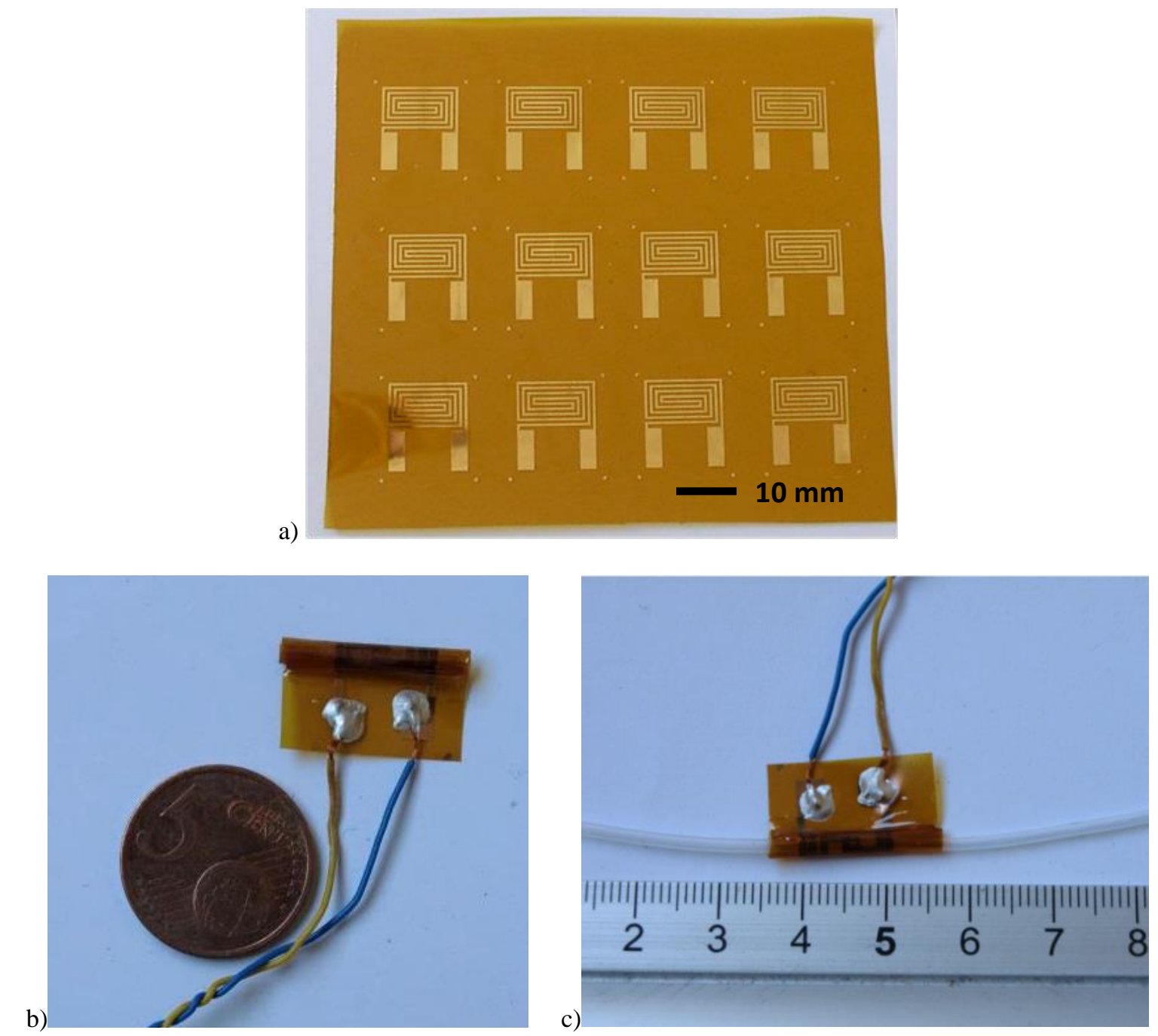

Figure 2: Implementation process of our tubular FGP: images of a) multiples micro-hotplates printed in a row b) the rolled up micro-hotplate compared to 5 Euro cents and c) the final device with fluidic interconnects.

\section{Characterization and optimization}

\subsection{Thermal optimization}

The design of the printed micro-hotplate was supported through FEM simulations using COMSOL and validated by thermal mapping experiments using micro-thermocouples [14]. During simulations, the thermal conductivity of the PI film was set at $0.12 \mathrm{~W} . \mathrm{m}^{-1} . \mathrm{K}^{-1}$ according to datasheet of the material and the temperature coefficient of resistance (TCR) of the gold heater was determined experimentally from experiments and fixed at $0.002 \mathrm{ppm} /{ }^{\circ} \mathrm{C}$. The convection coefficient was then extracted by fitting the results from simulations with those from the thermal measurements and was set at $25 \mathrm{~W} \cdot \mathrm{m}^{-2} \cdot \mathrm{K}^{-1}$. Thermal mapping experiments and simulations have shown a uniform distribution of temperature through the active area of the FGP with a gradient from the center to edge of less than 50 ${ }^{\circ} \mathrm{C}$ when it is heated up at $350^{\circ} \mathrm{C}$ (Figure 3). Our FGP allows reaching $350{ }^{\circ} \mathrm{C}$ with a power of $1700 \mathrm{~mW}$ i.e. 15 $\mathrm{mW} / \mathrm{mm}^{2}$ thanks to the combination of gold nanoparticles-based heater and Kapton foil substrate (Figure 4). Besides, the foil gas preconcentrator is still working even after 70 heating cycles in a row at $200{ }^{\circ} \mathrm{C}$ during $5 \mathrm{~min}$ which corresponds to its current operating conditions (Figure 5). 


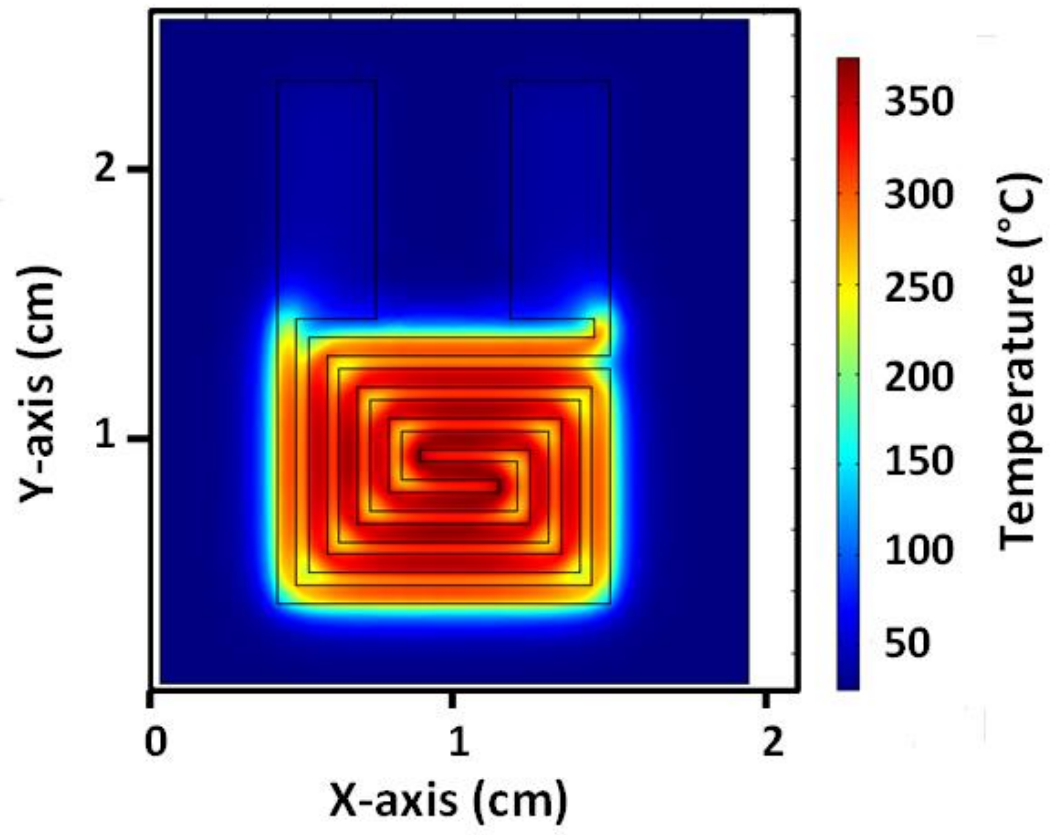

Figure 3: Thermographic simulation obtained on COMSOL 4.2 of the micro-hotplate operating at a power of $1700 \mathrm{~mW}$.

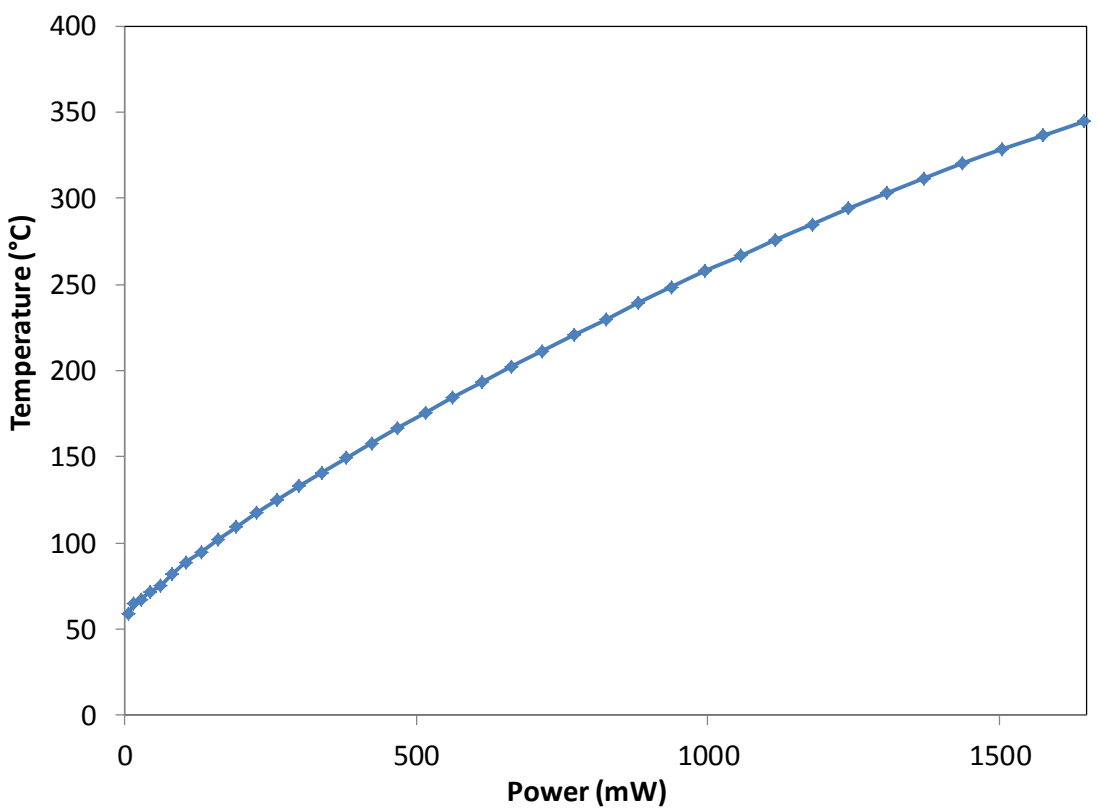

Figure 4: Temperature $\left({ }^{\circ} \mathrm{C}\right)$ versus Power $(\mathrm{mW})$ of the gold printed micro-hotplate. 


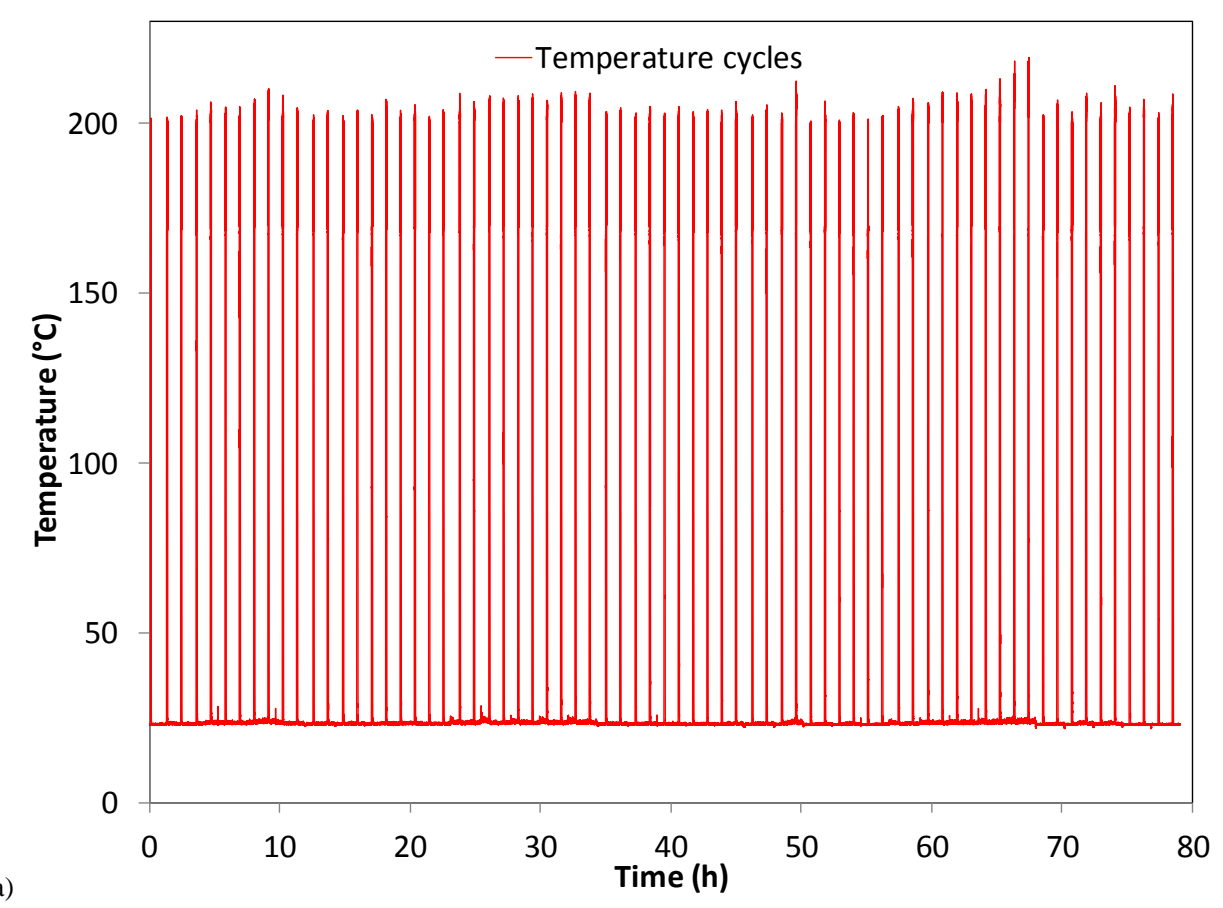

a)

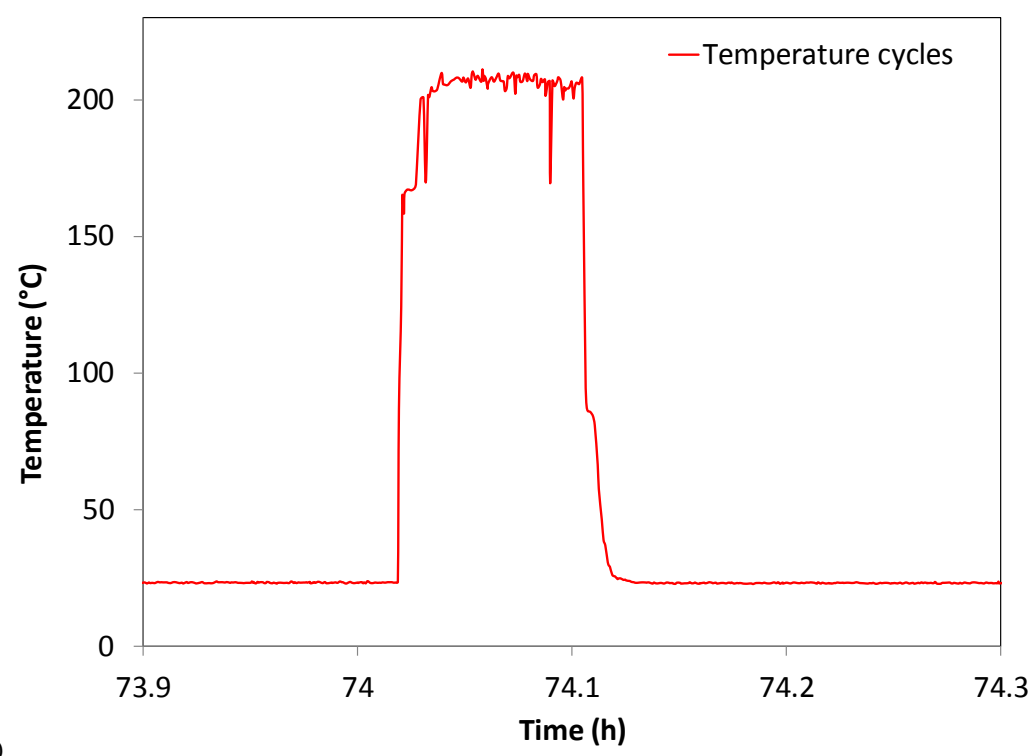

Figure 5: a) 70 successive temperature cycles at $200^{\circ} \mathrm{C}$ during $5 \mathrm{~min}$ obtained with the $\mathrm{FGP}$ and b) zoom on one temperature cycle at $200^{\circ} \mathrm{C} @ 5 \mathrm{~min}$.

\subsection{Fluidic characterization}

After the rolling up and sealing of the fluidic interconnects, the pressure drop was measured at flow rates from 66 $\mathrm{mL} / \mathrm{min}$ to $4500 \mathrm{~mL} / \mathrm{min}$. This fluidic characterization showed that the FGP is usable at high flow, up to $4.5 \mathrm{~L} / \mathrm{min}$ without any damage (Figure 6) while our previously reported silicon gas preconcentrators (SGP) [2] could not exceed $1 \mathrm{~L} / \mathrm{min}$ at 5 bars.. Moreover the flow rate of the FGP is mainly limited by the currently used fluidic interconnections. However, the inlet and outlet of FGP could be adjusted during rolling up of the micro-hotplate for allowing larger fluidic interconnects in regards to the requirements of the application. 


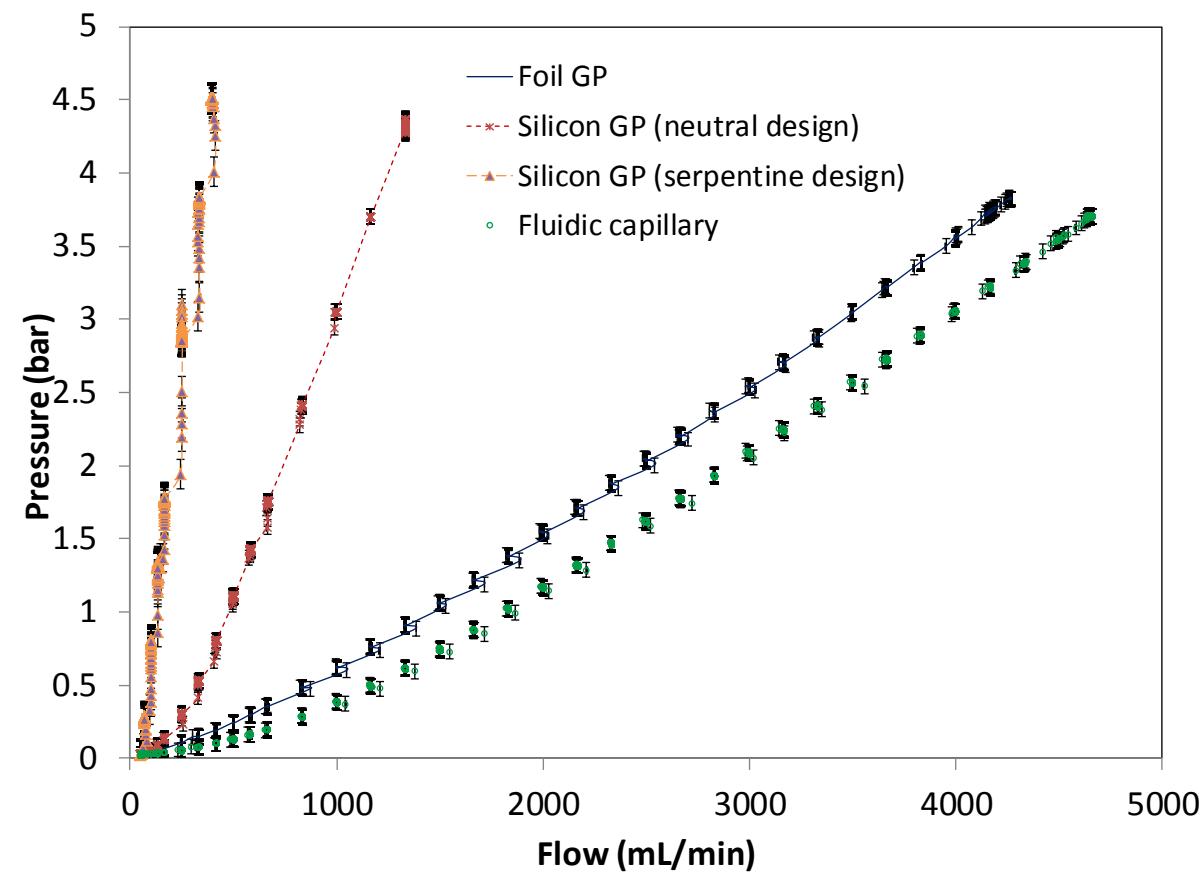

Figure 6: Pressure (bar) versus flow ( $\mathrm{mL} / \mathrm{min}$ ) obtained with a FGP filled with 1mg of Carbopack B compared to two silicon gas preconcentrators neutral and serpentine designs reported in $[5,13]$ filled with $1 \mathrm{mg}$ of Carbopack B and a fluidic capillary.

\section{Results on gas preconcentration}

\subsection{Test bench}

The test bench implemented for this study consisted of a gas generator (from Owlstone Nanotech) using permeation tubes, mass flow-meters for dilution steps and a climatic chamber containing the FGP and the detection system (Figure 7). The climatic chamber was set at $40^{\circ} \mathrm{C}$ to avoid any condensation between the gas preconcentrator and the detector. The detection system is a photon ionization detector (PID - from RAE Systems). Different permeation tubes (Benzene, Toluene, Nitrobenzene and Acetophenone) were purchased and calibrated by weight loss measurement at a given temperature for estimating their permeation rates.

Experiments were conducted at various adsorption and desorption flow rates for finding optimum operating conditions while the adsorption time was reduced from $10 \mathrm{~min}$ for previous silicon devices to down $5 \mathrm{~s}$ for shortening the preconcentration duty cycle down $1 \mathrm{~min}$. As the desorption time is fixed by the desorption rate, the heating rate was fixed at the maximum value achievable in our experimental setup, up to $40{ }^{\circ} \mathrm{C} / \mathrm{s}$.

Blank tests (without injection of the target gas) were conducted before and after each measurement for verifying the good functioning of the set-up.

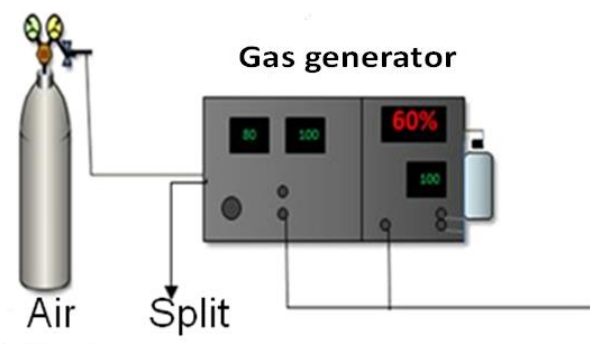

Photo-Ionization Detector (PID)

\section{Cylinder}

Figure 7: Schematic diagram of the test bench for the generation and detection of VOCs in sub-ppb range 


\subsection{Benzene}

First experiments were realized with Carbopack B adsorbent, under $250 \mathrm{ppb}$ of benzene at a constant adsorption flow rate of $667 \mathrm{~mL} / \mathrm{h}$ but at different adsorption times $(60,10$ and $5 \mathrm{~s})$ and desorption flow rates (67 and 84 $\mathrm{mL} / \mathrm{min}$ ). As shown in figure 8, the three first preconcentration cycles with adsorption times of 60,10 and $5 \mathrm{~s}$ were obtained at a desorption flow rates of $84 \mathrm{~mL} / \mathrm{min}$ whereas the three following cycles were done at a desorption flow rate of $67 \mathrm{~mL} / \mathrm{min}$. These results demonstrated the fact that lower is the desorption flow rate, higher is the desorption peak. Therefore all following tests were conducted at a desorption flow rate of $67 \mathrm{~mL} / \mathrm{h}$ which corresponds to the lowest flow rate reachable with our current setup. Experiments showed also a preconcentration factor higher than the ones we observed for our silicon devices reported in [5] thanks to the use of high adsorption flow rates. Indeed, the PF obtained with our FGP is about 68 when it was exposed to $250 \mathrm{ppb}$ of benzene during $1 \mathrm{~min}$ while the silicon device displayed a PF of 56 for an adsorption time of 10min. With our FGP, the adsorption time could even be reduced down to $5 \mathrm{~s}$ while maintaining an appropriate PF. Besides, blank tests done before and after each measurement show no memory effect and prove the conformity of our set-up.

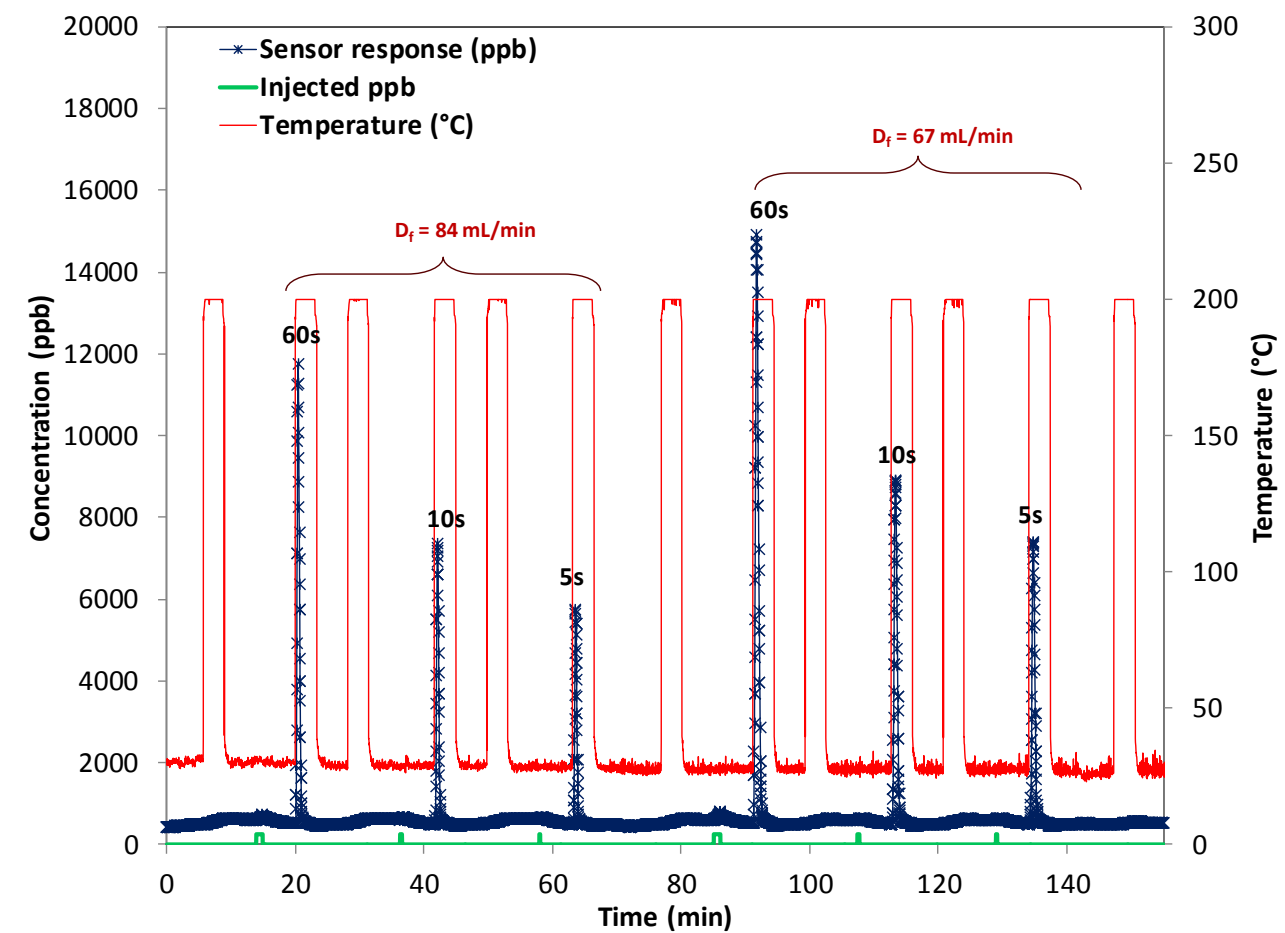

Figure 8: Six cycles of preconcentration from a FGP filled with 1mg of Carbopack B when exposed to $250 \mathrm{ppb}$ of benzene during 60,10 and $5 \mathrm{~s}$ at adsorption flow rate of $667 \mathrm{~mL} / \mathrm{min}$ and desorbed at $200{ }^{\circ} \mathrm{C}$ with desorption flow rates $\left(D_{\mathrm{f}}\right)$ of 83 and $66 \mathrm{~mL} / \mathrm{min}$, respectively.

\subsection{Toluene}

The reproducibility of the preconcentration cycles was also tackled under toluene and Carbopack B adsorbent through experiments in which three preconcentration cycles were realized under the same experimental conditions, the results being shown in Figure 9. Indeed, the same height was obtained for the three different desorption peaks showing a good reproducibility of the FGP. These experiments show also a PF under toluene of about 200, 3 times higher than the ones under benzene tested under the same conditions.

Nevertheless, a slight breakthrough is observed after $1.5 \mathrm{~min}$ when operating at $250 \mathrm{ppb}$ of toluene during $2 \mathrm{~min}$ with an adsorption flow of $1 \mathrm{~L} / \mathrm{min}$. 


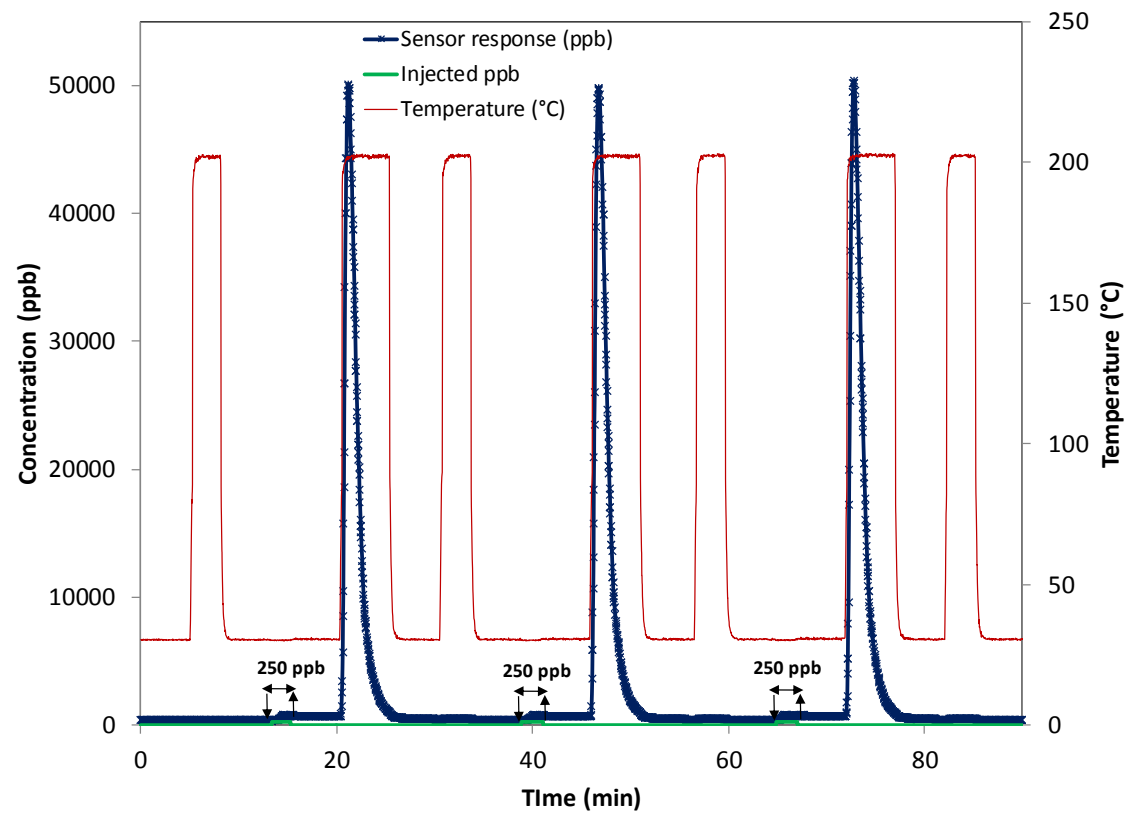

Figure 9: Three cycles of preconcentration from a FGP filled with 1mg of Carbopack B when exposed to $250 \mathrm{ppb} @ 2 \mathrm{~min}$ of toluene at $1 \mathrm{~L} / \mathrm{min}$ and desorbed at $200{ }^{\circ} \mathrm{C}$ with a flow of $67 \mathrm{~mL} / \mathrm{min}$

After having set the desorption flow rate at $67 \mathrm{~mL} / \mathrm{min}$ and tested the reproducibility, the optimal adsorption flow rate was addressed under $125 \mathrm{ppb}$ of toluene at various adsorption flow rates (from 667 to $1667 \mathrm{ml} / \mathrm{h}$ ) and adsorption times (from 120 to $5 \mathrm{~s}$ ). Toluene was chosen because of its low vapour pressure and also a stronger adsorption bond compared to benzene which is desired for avoiding any early breakthrough when operating at flow rates up to 1000 $\mathrm{mL} / \mathrm{min}$. A lower concentration set at $125 \mathrm{ppb}$ is also required for the same reason.

These experiments showed an optimal adsorption flow rate of $1 \mathrm{~L} / \mathrm{min}$ for each adsorption time (Figure 10). Since the amount of gas molecules injection through the adsorbent bed increases with the adsorption flow rate, one could easily assume that PF is proportional to the adsorption flow rates. However, there is an limitation at high flow where the adsorption capacity of the adsorbent bed is drastically reduced (depending on its length) given that the probability for a gas molecule to be adsorbed on the adsorbent bed drops with the increase of the speed of gas molecules. Therefore, the adsorption flow rate of $1 \mathrm{~L} / \mathrm{min}$ corresponds to the trade-off between a high flow rate and a sufficiently long residence time for the gas molecules to be adsorbed.

The figure 10 demonstrates again that 5 seconds of adsorption is reasonable even for low concentrations such as $125 \mathrm{ppb}$ of toluene. 


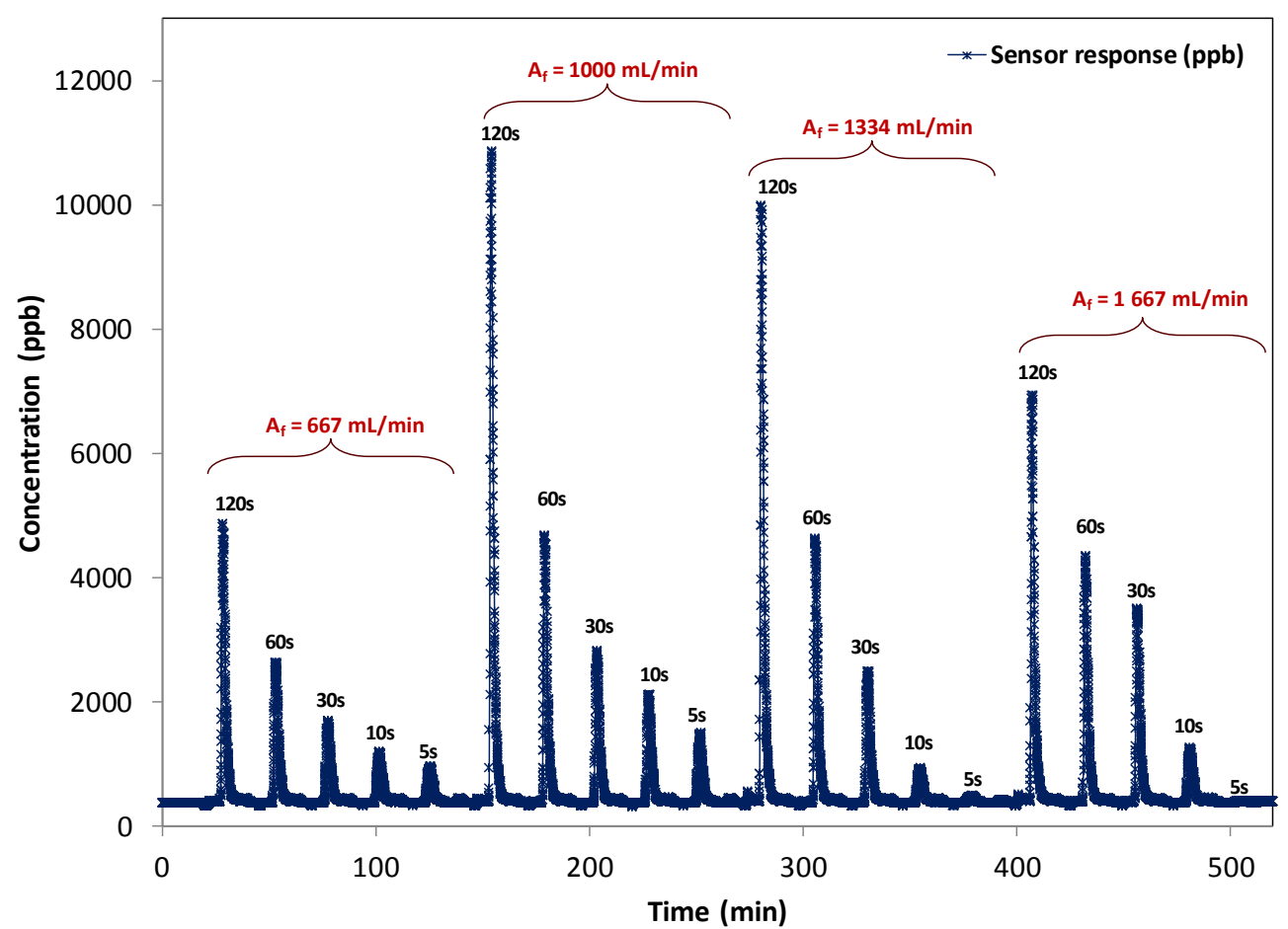

Figure 10 Twenty cycles of preconcentration from a FGP filled with 1mg of Carbopack B when exposed to 125 ppb of toluene during 120, 60, 30,10 and $5 \mathrm{~s}$ at adsorption flow rates $\left(\mathrm{A}_{\mathrm{f}}\right)$ of $667,1000,1334$ and $1667 \mathrm{mLmin}$ and desorbed at $200{ }^{\circ} \mathrm{C}$ with desorption flow rates $\left(\mathrm{D}_{\mathrm{f}}\right)$ of 66 $\mathrm{mL} / \mathrm{min}$, respectively.

\subsection{Nitro-benzene}

Nitro-aromatic compounds were also targeted since explosives detection is one of the aims of the project funding this work. Nitrobenzene seems the ideal target gas for preliminary tests on nitro-aromatic explosives because of its higher volatility compared to DNT or TNT which makes easier its generation and detection.

First tests with the couple Carbopack B - nitrobenzene at a desorption temperature of $200^{\circ} \mathrm{C}$ showed a spreading of the desorption peak meaning that a temperature of $200^{\circ} \mathrm{C}$ is not high enough with respect to the strong bonding character of nitrobenzene compounds. To overcome this issue, the desorption temperature was increased up to $250^{\circ} \mathrm{C}$ (maximum temperature allowed by our current setup.) The figure 11 displays a PF of 8 when 250ppb of nitrobenzene was injected during $2 \mathrm{~min}$ at a flow rate of $1 \mathrm{~L} / \mathrm{min}$ and desorbed at $67 \mathrm{~mL} / \mathrm{min}$. However, the PF under nitrobenzene is much lower than ones under benzene or toluene maybe because of a possible re-adsorption of nitrobenzene molecules through the outlet tubing of the setup due to their stickiness. However, the foil gas preconcentrator could be suitable for security application like explosives detection after few improvements regarding the FGP and the test bench. 


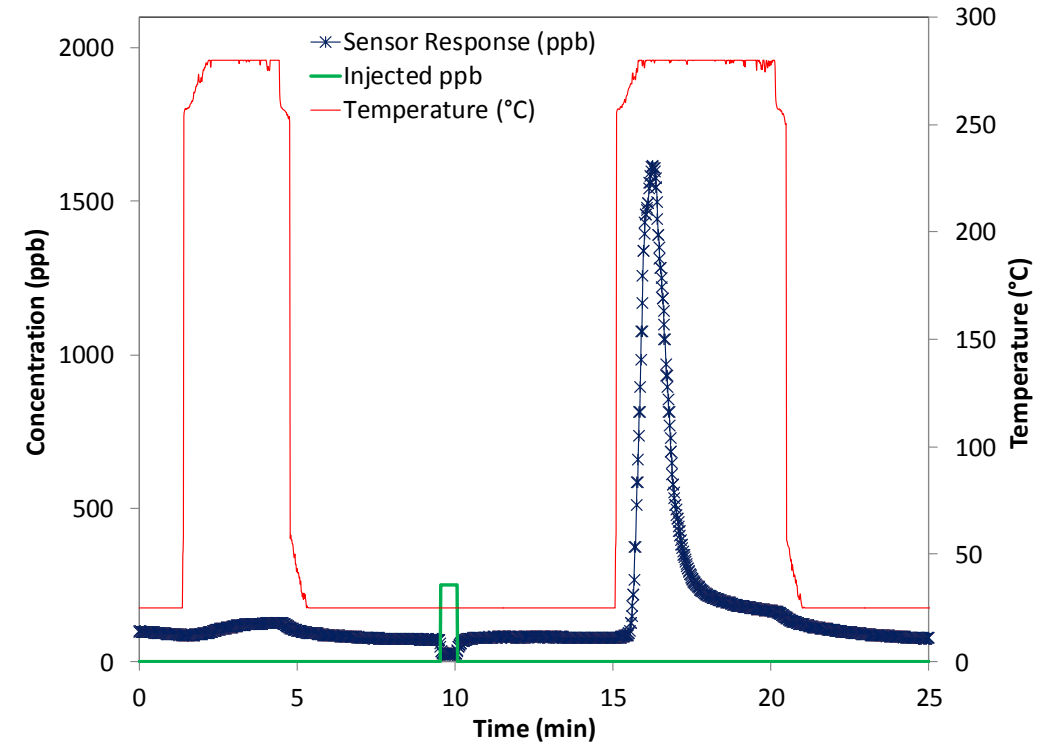

Figure 11: A cycle of preconcentration from a FGP filled with 1mg of Carbopack B when exposed to 250 ppb@ 1 min of Nitrobenzene at 1 L/min and desorbed at $200^{\circ} \mathrm{C}$ with a flow of $66 \mathrm{~mL} / \mathrm{min}$

\subsection{Acetophenone}

In order to prove the versatility of the technology, we have filled our foil gas preconcentrator with Tenax adsorbent following the same protocol as with Carbopack B. The Tenax-based FGP was then tested under acetophenone which is a cigarettes additive and an excipient used in many legal and illegal psychotic drugs, hence a good candidate in context of smuggling prohibited goods. Long used in solid phase micro-extraction (SPME) as adsorbent fiber, Tenax was also chosen because of its low desorption temperature towards very sticky compounds like acetophenone.

Hence, this test demonstrates on one hand, the versatility of our foil gas preconcentrator which can be easily filled with any adsorbent in regards of the target gas, and on another hand, the feasibility of acetophenone preconcentration using Tenax adsorbent (Figure 11).

However, the performance of the couple Tenax-Acetophenone is lower than one the couple Carbopack-Benzene $(\mathrm{PF}=25)$. This low $\mathrm{PF}$ could be explained by the low adsorption capacity of Tenax towards VOCs in comparison to carbon-based adsorbents.

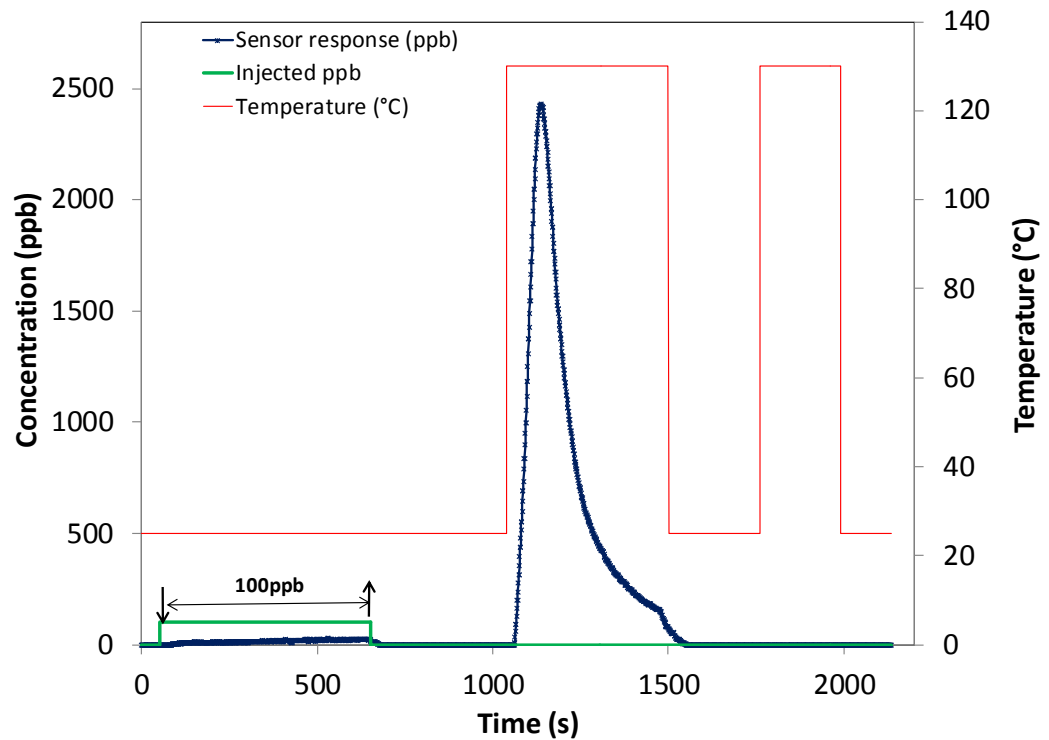

Figure 12: A cycle of preconcentration obtained from a FGP filled with 1mg of Tenax TA when exposed to 100 ppb@10 min of acetophenone at $667 \mathrm{~mL} / \mathrm{min}$ and desorbed at $130{ }^{\circ} \mathrm{C}$ with a flow of $66 \mathrm{~mL} / \mathrm{min}$ 


\section{Conclusions}

We have successfully demonstrated the fabrication and testing of a versatile FGP based on gold heater printed on a polyimide foil. Successful operation of the devices was demonstrated for the preconcentration of benzene, toluene, nitrobenzene and acetophenone. The FGP shows better performances than silicon preconcentrators tested under the same conditions thanks to their high flow rate capability, which is obtained by rolling up the flexible hotplate device.

We are now working on the maximization of this PF by increasing the inlet/outlet diameter and the length of the FGP during the rolling up for a higher flow rates and longer stay time for target molecules, respectively. This FGP concept could be extended to numerous others applications like, breath analysis by changing the adsorbent and/or the implementation protocol. Another perspective is the deposition of adsorbent materials by printing techniques.

\section{Acknowledgements}

The authors are grateful to the FP7 EU, SNIFFER for the funding of this work (grant no: 285203).

\section{References}

[1] http://www.pall.com/pdfs/Microelectronics/MEGPICO1000EN.pdf

[2] http://www.defianttech.com/pdfs/Pittcon\%202014\%20A\%20MicroGC\%20Based\%20Chemical\%20Analysis\%20System.pdf

[3] W. R. Collin, G. Serrano, L. K. Wright, H. Chang, N. Nuñovero, E. T. Zellers, Microfabricated gas chromatograph for rapid, trace-level determinations of gas-phase explosive marker compounds, Analytical Chemistry 86 (2014) 655-663.

[4] M. Camara, P. Breuil, D. Briand, J. Viricelle, C. Pijolat and N. F. de Rooij, Preconcentration Modeling for the Optimization of a Micro Gas Preconcentrator Applied to Environmental Monitoring, Anal. Chem., 87 (2015) 4455-4463.

[5] E.H.M. Camara, P. Breuil, D. Briand, N. R. de Rooij and C. Pijolat, A micro gas preconcentrator with improved performance for pollution monitoring and explosives detection. Analytica Chimica Acta vol. 688 (2011) 175-182.

[6] M. Martin, M. Crain, K. Walsh, R. E. McGill, E. Houser, J. Stepnowski, S. Stepnowski, H.-D. Wu, S. Ross, Microfabricated vapor preconcentrator for portable ion mobility spectroscopy. Sensors and actuators B vol. 126 (2007) 447-454.

[7] I. Voiculescu, R. A. McGrill, M. E. Zaghoul, Micropreconcentrator for enhanced trace detection of explosives and chemical agents. IEEE Sensors journal, Vol. 6, NO. 5, October 2006.

[8] A.M. Ruiz, I. Gracia, N. Sabate, P. Ivanov, A. Sanchez, M. Duch, M. Gerboles, A. Moreno, C. Cane, Membrane-suspended microgrid as a gas preconcentrator for chromatographic applications. Sensors and Actuators A vol. 135 (2007) 192-196.

[9] G. Serrano, T. Sukaew, E. T. Zellers, Hybrid preconcentrator/focuser module for determinations of explosive marker compounds with a micro-scale gas chromatograph, Journal of Chromatography A, 1279 (2013) 76-85.

[10] J. Courbat, D Briand, L. Yue, S. Raible and N. F. de Rooij, Drop-coated metal-oxide gas sensor on polyimide foil with reduced power consumption for wireless applications, Sensors and Actuators B: Chemical 161 (2012) 862-868.

[11] E. Danesh, F. Molina-Lopez, M. Camara, A. Bontempi, A. Vásquez Quintero, D. Teyssieux, L. Thiery, D. Briand, N. F. de Rooij, K. C. Persaud, Development of a new generation of ammonia sensors on printed polymeric hotplates, Analytical Chemistry 86 (2014) 8951-8958.

[12] B. Alfeeli, V. Jain, R. K. Johnson, F. L. Beyer, J. R. Heflin and M. Agah, Characterization of poly(2,6diphenyl-p-phenylene oxide) films as adsorbent for microfabricated preconcentrators. Microchemical Journal V. 98 (2011) 240-245.

[13] M. Camara, C. Pijolat, L. Guillot, P. Breuil, D. Briand, N. de Rooij, Micro gas preconcentrator in porous silicon filled with a carbon absorbent, Sens \& Act B, 148 (2010) 610-619.

[14] L. Thiery, S. Toullier, D. Teyssieux, D. Briand, Thermal contact calibration between a thermocouple probe and a micro-hotplate, Journal of Heat Transfer, Vol.130, 9 (2008) 091601-091608. 